Brit. J. industr. Med., 1951, 8, 91.

\title{
AN INFLUENZA EPIDEMIC IN INDUSTRY
}

BY

\section{A. LLOYD POTTER}

(RECEIVED FOR PUBLICATION FEBRUARY 10, 1951)

The recent influenza epidemic in Britain first appeared in Tyneside in the latter half of December, 1950 , and is believed to have had its origin in Scandinavia (Lancet, 1951). Shortly afterwards there was an outbreak in Belfast, and almost concurrently in Merseyside, where the towns of Widnes and Runcorn, the centre of the chemical industry, were particularly affected. The epidemic received much publicity in the press, and this district was wrongly assumed by many to be the starting point of the outbreak in Britain.

This paper is a brief account of the effects of the influenza epidemic in six chemical works in the Widnes and Runcorn area with a total population of 7,928. The processes in these factories are, in the main, continuous, and the factories must, at all costs, be prevented from closing down.

The doctor in industry, and particularly in a. chemical works, must always be on the watch for toxic manifestations related to plants or processes. However, in a chemical works such manifestations are relatively uncommon, and much of the doctor's time is devoted to the diagnosis and preliminary treatment of constitutional illness to which anyone is subject. My attention was drawn to the symptoms which appeared on December 18 in the six factories coming under my supervision. By noon in one of the factories 14 persons had reported to the medical department complaining of headache, aching limbs and back, dry throat, tracheitis, and pyrexia up to about $102^{\circ} \mathrm{F}$. All appeared to be suffering from typical influenza. A rapid check proved that the cases were not all concentrated in one part of the works, but were coming from widely separated sections. The other five factories had the same experience and there was no doubt that the disease was rapidly reaching epidemic proportions. Little could be done to treat the patients in the factory medical departments, which became clearing houses for diagnosis and transmission of patients exhibiting the typical symptoms. The factory car services were fully occupied in conveying patients to their homes and delivering notes from the works medical officers to the general practitioners.

It is often impossible to distinguish clinically. between influenza $\mathbf{A}$ and undifferentiated acute respiratory disease, as the Commission on Acute Respiratory Diseases (1948) found in their investigation of an influenza $\mathbf{A}$ epidemic in military training camps in North Carolina. In the cases seen in our medical departments pyrexia had to be the chief factor in the decision to send a patient home or allow him to continue at work.

Within a few days, no doubt because their own staff were also depleted, the local press reported the story of the influenza wave and its effects on the factory population, and this was soon taken up and expanded, in no uncertain terms, by the national press. It became headline news and drew the anticipated answer from medical authorities that, in fact, no epidemic existed. In spite of this, patients continued to arrive in ever increasing numbers at the factory medical department and, in turn, general practitioners became more and more hard pressed. The publicity continued and so alarmed the population both in and out of the factories that the figures for sickness absence rose alarmingly. Ordinary colds, minor pharyngitis, headaches and lumbago, were all labelled influenza, and the overworked practitioners with queues outside their surgeries could not possibly be accurate in diagnosis or certification. Their chief preoccupation was to decide which patients required their attention and which could look after themselves. It was quite impossible for them to visit all the sufferers, and, as one doctor observed, he was only able to prescribe on the telephone and follow up with a visit if the temperature did not subside in three days.

The incidence steadily increased until the end of the first week in January, 1951, but, thereafter, the numbers fell steadily, while other parts of the country felt the impact of the epidemic and the health authorities agreed that the disease had indeed reached minor epidemic proportions. 


\section{Symptomatology}

The disease, fortunately, was of a mild type, and uncomplicated cases exhibited the typical symptoms of fever, headache, aching back and limbs, pharyngitis and tracheitis. Pyrexia continued for about 72 hours and the patient was left in a debilitated and depressed condition, with bronchitis which persisted for about two to three weeks. The average duration of sickness absence in uncomplicated cases was 14-21 days, the longer period of absence being necessary for manual workers. The incidence of bronchopneumonia was high in the older age groups, and in the general population the death rate from influenzal complications rose steeply in old people.

\section{Distribution of Cases}

In the chemical industry it is uncommon to have large groups of workers employed on any one process. Such groups are only found in offices, in general services workshops, and in packing and distribution sections. This fact probably played a part in limiting the spread of infection by direct contact, and it was noticeable that in one factory the highest incidence was in a packing section staffed by 121 girls. Here the figure for absenteeism rose on New Year's day to $47.1 \%$ compared with $24.7 \%$ elsewhere in the same factory.
Absenteeism from causes other than sickness is to be expected on this day, but the comparison between different departments should be valid. The corresponding figure for the office staff rose to $13 \cdot 1 \%$ only, in spite of the greater crowding together and contact which, of necessity, occurs in large offices.

These figures appear to contradict the suggestion that a high incidence may be expected in more crowded places, and it is a matter for speculation why there should be such a difference between the office staff and the packing section. The latter is largely a population of young girls, while the office staff is composed of $75 \%$ males and $25 \%$ females. The girls are employed on repetitive jobs and, although working on an incentive bonus scheme, may be expected to take an unofficial holiday at New Year more readily than would the office staff. This point is confirmed by a comparison of the figures for January 3, when $28.9 \%$ were absent from the packing section and $13.7 \%$ from the offices. Moreover, it is possible that the unfortunate publicity given to the epidemic influenced the more youthful employees to absent themselves for minor complaints, for which, normally, they would obtain treatment in the works medical department.

Fig. 1 shows the daily number of absentees in the six Merseyside factories during the period December 11, 1950, to January 25, 1951. The

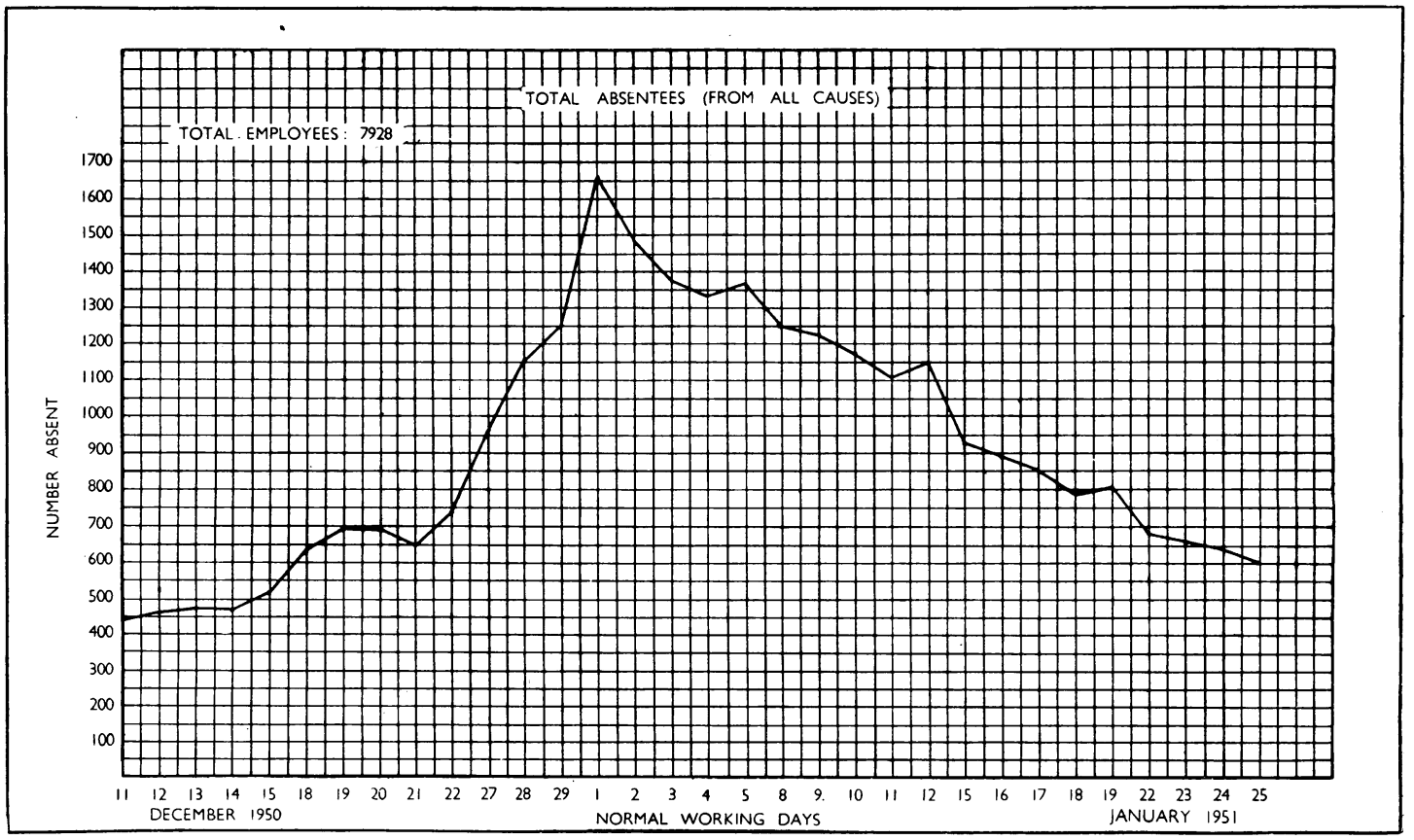

FIG. 1 


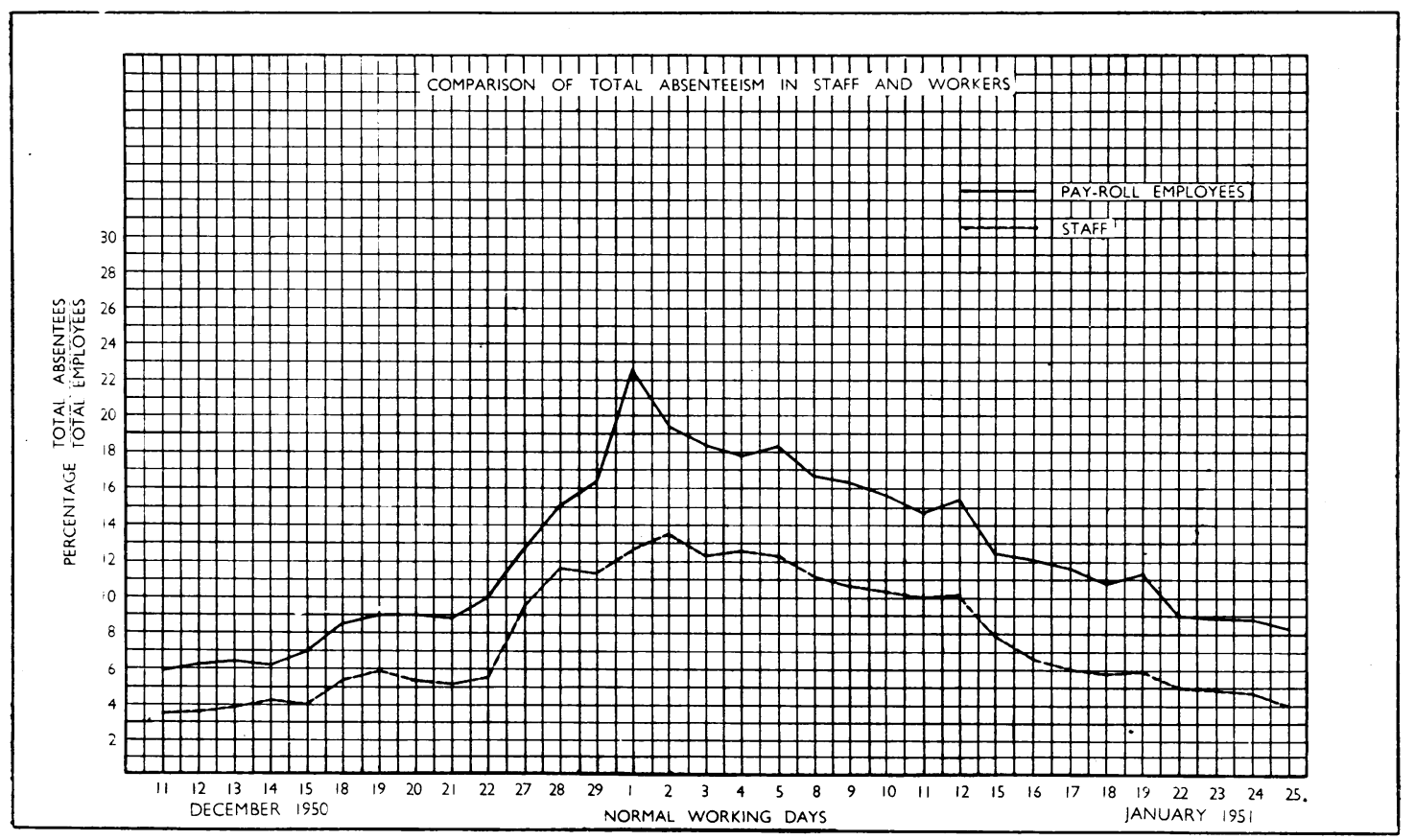

FIG. 2

effect on industry has perforce to be estimated by total absenteeism from all causes, and it must, therefore, be realized that the figures shown in the graph refer to this and not solely to absence from influenza. Normal absenteeism from all causes in the same factories averages $6 \%$ (i.e. about 500 persons), at this time of the year, and it can be assumed that the difference between this figure and those shown are almost entirely due to the epidemic or fear of it.

Fig. 2 compares the percentage of staff and payroll* employees absent each day. The latter normally have a higher absence rate, possibly due to their shift hours, exposure to cold and wet weather, and the greater physical effort demanded by their work. It is suggested that the proportionately higher absence of pay-roll workers during the height of the epidemic was because they were more prone than staff to treat minor complaints as influenza.

\section{Effect on Industry}

The wide distribution of cases and the natural dispersal of employees in the chemical industry fortunately prevented any necessity for closing down processes, and there was, consequently, no loss of production. The epidemic, however, gave rise to a

\footnotetext{
* Pay-roll employees are mostly manual workers, a minority of whom are paid full wages while they are absent.
}

considerable amount of overtime, and many men were required to work double shifts in order to keep processes going. Occasional double shift and overtime working have no ill effects, but when continued indefinitely there must be a lowering of resistance, due to fatigue, which is a probable factor in the further spread of this type of infection. It is interesting to note that those workers who suffered from typical colds, with only naso-pharyngeal symptoms, did not develop true influenza, and were able to continue at their jobs. Thus, early observation and reassurance of such cases was an important factor in preventing unnecessary absence. The short duration of absence in uncomplicated cases also played an important part in the maintenance of full production, for if absence had been unduly prolonged, there is little doubt that the fatigue and lowered resistance experienced by those who did not themselves suffer from the disease would eventually have led to a greater disruption of normal working.

The numbers involved in the epidemic were the highest recorded for any reason for very many years in this industry. In spite of the mild type of disease, therefore, the effects could have been very serious if the peak had not been passed so quickly and if those who remained at work had not so willingly shouldered the extra burden. 


\section{Prophylaxis}

Many requests were passed to the medical department by management and workers for some means of combating the spread of infection within the factories. Careful consideration was given to suggestions for spraying process buildings and offices with bactericidal solutions, to the issue of antiseptic tablets, to regular attendance for gargles, and to many other similar ideas. None of these measures has been proved to have any effect in preventing the spread of influenza. When it is realized that most people in industry spend less than one-third of their time at work, and the other two-thirds at home, in cinemas and places of entertainment, in buses and trains, shops, football matches and the like, it is probable that any method intended to obviate or reduce the chance of becoming infected at work will have little effect on the total incidence of the disease. It is surely true to say that influenza is spread more readily in public transport or in crowded places of entertainment than in well ventilated, airy process buildings in a chemical works. True, there is a considerable psychological effect produced by spraying buildings and telephones and by issuing some form of antiseptic lozenge. After due consideration, therefore, our views on the matter were made plain to both workers and management through the medium of the joint consultation committees, and no such measures were introduced. All employees, however, were advised to avoid crowds as much as possible, and to report to the works medical department if any of the recognized symptoms of the disease were experienced. The short incubation period of influenza can ensure the early removal of a sufferer from contact with others, and this will probably control the spread of infection much more positivelv than the use of the preventive measures which a community usually demands. Though such measures may be classed as excellent showmanship there is no evidence that they have any real effect in retarding the intensity of an epidemic.

The doctor in industry may at first sight appear to be quite helpless in controlling an epidemic of influenza in his factories. If, however, his efforts are concentrated on early diagnosis of the disease, preliminary treatment, and the removal of the infectious persons from the factory to the care of their own practitioners in their own homes, he will have done much to prevent the spread of the disease. Moreover, if he can then advise employees on general precautions to be taken and can separate the true cases of influenza from those who only think they have contracted the disease, he will have done much to maintain normal production in the factory.

\section{Summary}

A short description is given of the recent epidemic of influenza which attacked the Merseyside towns of Widnes and Runcorn.

The effects on workers and staff in the chemical industry are discussed.

Attention is drawn to the dangers of publicity in epidemics of this type.

The value or otherwise of prophylactic measures within the factory is discussed, and the role of the industrial medical officer in an influenza epidemic is suggested.

\section{REFERENCES}

Commission on Acute Respiratory Diseases (1948). Amer. J. Hyg., 48, 263.

Lancet (1951). 1, 217. 